\title{
BUSINESS CYCLE FLUCTUATIONS AND THE LIFE CYCLE:
} HOW IMPORTANT IS ON-THE-JOB SKILL ACCUMULATION?

\author{
Gary D. Hansen \\ Selo Imrohoroglu \\ Working Paper 13603 \\ http://www.nber.org/papers/w13603
NATIONAL BUREAU OF ECONOMIC RESEARCH
1050 Massachusetts Avenue
Cambridge, MA 02138
November 2007

We thank Larry Jones, Burhanettin Kuruscu and Bob Lucas for comments on an earlier version of the paper. The views expressed herein are those of the author(s) and do not necessarily reflect the views of the National Bureau of Economic Research.

(C) 2007 by Gary D. Hansen and Selo Imrohoroglu. All rights reserved. Short sections of text, not to exceed two paragraphs, may be quoted without explicit permission provided that full credit, including (c) notice, is given to the source. 
Business Cycle Fluctuations and the Life Cycle: How Important is On-The-Job Skill Accumulation? Gary D. Hansen and Selo Imrohoroglu

NBER Working Paper No. 13603

November 2007

JEL No. E32,J22,J24

\begin{abstract}
$\underline{\text { ABSTRACT }}$
We study the effects of on-the-job skill accumulation on average hours worked by age and the volatility of hours over the life cycle in a calibrated general equilibrium model. Two forms of skill accumulation are considered: learning by doing and on-the-job training. In our economy with learning by doing, individuals supply more labor early in the life cycle and less as they approach retirement than they do in an economy without this feature. The impact of this feature on the volatility of hours over the life cycle depends on the value of the intertemporal elasticity of labor supply. When individuals accumulate skills by on-the-job training, there are only weak effects on both the steady-state labor supply and its volatility over the life cycle.
\end{abstract}

Gary D. Hansen

UCLA

Department of Economics

8283 Bunche Hall

Box 951477

Los Angeles, CA 90095

and NBER

ghansen@econ.ucla.edu

Selo Imrohoroglu

Department of Business Economics

School of Business Administration

University of Southern California

Los Angeles, CA 90089

selo@marshall.usc.edu 


\section{Introduction}

Inspired by the research agenda proposed by Lucas (1980), the equilibrium business cycle literature has demonstrated that surprisingly simple model economies display fluctuations with quantitative properties similar to those of business cycles experienced by actual economies. Most of this literature, beginning with Kydland and Prescott (1982), has studied versions of the infinite horizon stochastic growth model calibrated to match secular growth facts. Ríos-Rull (1996) showed that this basic claim extends to stochastic life cycle economies as well.

Life cycle models, being models of heterogeneous agents, have implications for business cycle properties about which the infinite horizon model is silent. In particular, individuals in these models respond to aggregate shocks differently depending on age. Understanding why and how individuals respond to business cycle shocks as they grow older is important for understanding how the properties of business cycles might change as the population ages and for evaluating government policies that affect individuals differently depending on age or, immigration policies for example, that might change the age composition of the population. ${ }^{1}$

Previous work [Ríos-Rull (1996) and Gomme, Rogerson, Rupert and Wright (2004)] has documented the behavior of time averages of market hours worked per person by age and the volatility over time of hours by age from U.S. time series data and compared this with the same statistics computed from simulations of a life cycle model. ${ }^{2}$ In the data, the standard deviation of hours displays a U-shape over the life cycle: volatility is high when young, falls as individuals age reaching a minimum and remaining flat during prime age, and then increases as individuals reach retirement age. Market hours worked per person increases with age, remains flat from age 25-55, and falls as individuals approach the normal retirement age.

These papers establish that a crucial modeling feature needed to account for these life cycle properties of hours worked is wages that change over the life cycle due to age specific human capital differences. In particular, an hour of labor from a younger worker is assumed to provide fewer productive

\footnotetext{
${ }^{1}$ See Jaimovich and Siu (2007) for evidence that demographic change has had a significant effect on business cycle volatility.

${ }^{2}$ These papers follow the real business cycle tradition of measuring business cycle volatility by computing the percent standard deviation of time series that has been detrended using the Hodrick-Prescott filter.
} 
labor services than an hour worked by a prime age worker due to exogenous efficiency weights.

In actuality, of course, the differences in productivity by age are not exogenous, but instead the result of human capital accumulation. In this paper, we explore how these findings are affected when the age-varying wages are not due to exogenous time invariant efficiency parameters, but the result of endogenous on-the-job skill accumulation. While young workers may be less productive than prime age workers and therefore earn less per hour, the total compensation of these younger workers that they take into account when making their labor supply decision also includes whatever return from experience they receive from working. That is, their effective wage may be much higher than their current wage given that they will be compensated with higher wages in the future as a result of the human capital they accumulate while on the job. This aspect of compensation is ignored when exogenous efficiency weights are assumed. In addition, the efficiency weights themselves will vary in response to shocks, potentially affecting the business cycle behavior of other endogenous variables.

We formulate and study the steady state and business cycle properties of a stochastic life cycle growth model calibrated to growth properties of the U.S. economy. ${ }^{3}$ Two forms of on-the-job skill accumulation are considered: learning by doing (LBD) and on-the-job training (OJT). In the first case, human capital is perfectly complementary with providing productive labor services-human capital is accumulated simply as a result of working. This contrasts with the second case where no productive labor services are provided while spending time engaged in OJT. Both have been extensively studied in the micro labor literature. ${ }^{4}$ We also compare the results obtained with on-the-job skill accumulation with those from an economy with exogenous age-specific wage parameters. All three economies are calibrated so that the steady state values for the age-specific wage parameters are identi-

\footnotetext{
${ }^{3}$ We assume the human capital production function used by Chang, Gomes, and Schorfheide (2002) in their analysis of learning by doing in an infinite horizon business cycle model. We modify this production function to allow for OJT in addition to LBD.

${ }^{4}$ Early papers on human capital accumulation that incorporates OJT include BenPorath (1967), Becker (1964), Blinder and Weiss (1976), Heckman (1976), Mincer (1974), and Rosen (1976). Shaw (1989) estimates a dynamic labor supply model with LBD. Imai and Keane (2004) estimate a structural model of labor supply with LBD and find that this feature can reconcile the relatively high labor supply elasticity that is consistent with aggregate data with the low elasticity typically found in the micro literature.
} 
cal.

We find that introducing OJT gives steady state and business cycle properties that are essentially identical to the case without skill accumulation. LBD, on the other hand, affects both sets of properties significantly. In particular, the impact of learning by doing is greater when labor supply is more elastic. The reason for this difference is that, in our calibrated economy, LBD affects labor market decisions at all ages, while OJT turns out to be important only during the early years of an individual's working life. Hence, exogenous efficiency weights appears to be a useful abstraction when studying the relationship between business cycles and the life cycle if skill accumulation occurs through OJT. If LBD is important for skill accumulation, exogenous efficiency weights may not be a good modeling assumption for studying this issue.

The remainder of this paper is organized as follows. The model is described in the next section and the third section describes the calibration. The findings are discussed in section 4 and concluding comments are provided in the section 5 .

\section{Model}

The economic setup follows the overlapping generations structure of Diamond (1965). Time is discrete $t=0,1, \ldots$ and the economy is subject to random fluctuations arising from shocks to the production technology as in Kydland and Prescott (1982).

\subsection{Demographics}

At each date $t$ a new generation of individuals is born that faces an uncertain life span. The population of new agents born each period grows at the time invariant rate $n$. We study the equilibrium properties of the model assuming stationary demographics (constant cohort shares), in which case $n$ is also the growth rate of the total population. Let $s_{i}$ denote the conditional probability of surviving from age $i$ to age $i+1$. Conditional on survival, individuals retire at age $I_{R}$. The maximum life span is $I$. Given $\left\{n,\left\{s_{i}\right\}_{i=1}^{I}\right\}$, the time invariant cohort shares, $\left\{\mu_{i}\right\}_{i=1}^{I}$, are given by

$$
\mu_{i}=\frac{s_{i-1}}{(1+n)} \mu_{i-1}, \text { for } i=2, \ldots, I
$$


and $\mu_{1}$ is determined such that

$$
\sum_{i=1}^{I} \mu_{i}=1
$$

\subsection{Technology}

There is a representative firm with access to a constant returns to scale Cobb-Douglas production function:

$$
Y_{t}=e^{z_{t}} K_{t}^{\alpha}\left(H_{t}\right)^{1-\alpha},
$$

where $K_{t}$ and $H_{t}$ are aggregate physical capital and labor inputs, respectively, and $\alpha$ is capital's share of income. Total factor productivity follows an $A R(1)$ process:

$$
z_{t+1}=\rho z_{t}+\nu_{t+1}, \quad \nu_{t+1} \sim N\left(0, \sigma_{\nu}^{2}\right), \quad 0<\rho<1, \quad z_{0} \text { given. }
$$

The capital stock depreciates at the rate $\delta$ and follows the law of motion

$$
K_{t+1}=(1-\delta) K_{t}+X_{t}
$$

where $X_{t}$ is aggregate investment in period $t$.

The firm is assumed to behave competitively, choosing capital and labor to maximize profits while taking the wage rate and rental rate of capital as given.

\subsection{Households' Problem}

An individual born at time $t$ maximizes expected discounted lifetime utility

$$
\sum_{i=1}^{I} \beta^{i-1}\left[\prod_{j=0}^{i-1} s_{j}\right]\left[\ln \left(c_{i, t+i-1}\right)+A \frac{\left(1-h_{i, t+i-1}-u_{i, t+i-1}\right)^{1-\gamma}}{1-\gamma}\right],
$$

where $\beta$ is the subjective discount factor, $c_{i, t+i-1}, h_{i, t+i-1}$, and $u_{i, t+i-1}$ are consumption, hours worked in production, and time spent in on-the-job training (OJT) for an age- $i$ individual at time $t+i-1$, respectively. The variable $h$ represents time spent producing goods in return for which an individual receives current labor income. OJT is also part of measured hours worked, 
but the individual is only compensated by higher wages in the future. Measured labor supply is equal to $h_{i, t+i-1}+u_{i, t+i-1}$. The parameter $A$ represents the importance of leisure in the period utility function and $\gamma$ determines the elasticity of labor supply. It can be shown that the compensated elasticity of labor supply is given by $\left(1-h_{i, t+i-1}-u_{i, t+i-1}\right) /\left(\gamma\left(h_{i, t+i-1}+u_{i, t+i-1}\right)\right) .^{5}$

At each age, the individual faces the following budget constraint:

$$
c_{i, t+i-1}+a_{i+1, t+i}=R_{t+i-1}\left(a_{i, t+i-1}+b_{t+i-1}\right)+w_{t+i-1} \varepsilon_{i, t+i-1} h_{i, t+i-1},
$$

where $R_{t+i-1}$ is the interest factor, $a_{i, t+i-1}$ is the amount of assets available at age $i, a_{i+1, t+i}$ is the amount of assets to be available at age $i+1, b_{t+i-1}$ is a lump sum distribution of accidental bequests, $w_{t+i-1}$ is the real wage at time $t+i-1$, and $\varepsilon_{i, t+i-1}$ is the efficiency or human capital of an individual at age $i$ and time $t+i-1$.

In addition, the individual's human capital over the working portion of the life cycle, $\left\{\varepsilon_{i, t+i-1}\right\}_{i=1}^{I_{R}-1}$, follows the law of motion

$$
\begin{aligned}
\ln \left(\frac{\varepsilon_{i+1, t+i}}{\bar{\varepsilon}_{i+1}}\right) & =\phi_{1} \ln \left(\frac{\varepsilon_{i, t+i-1}}{\bar{\varepsilon}_{i}}\right)+\phi_{2} \ln \left(\frac{x_{i, t+i-1}}{\bar{x}_{i}}\right), \\
x_{i, t+i-1} & = \begin{cases}h_{i, t+i-1} & \text { for learning-by-doing } \\
u_{i, t+i-1} & \text { for on-the-job training, }\end{cases}
\end{aligned}
$$

where $\varepsilon_{1, t}=\bar{\varepsilon}_{1}$ for all $t, \phi_{1} \in(0,1), \phi_{2}>0$. That is, all individuals are born with the same human capital. The variable $x_{i, t+i-1}$ is time spent on skill accumulation by an age $i$ individual at time $t+i-1$. Variables with bars above them indicate steady state values for the corresponding perfect foresight economy with $\sigma_{\nu}=0$.

Equation (7), as part of the household's optimization problem, implies that when the individual is making the leisure-labor choice at time $t+i-1$ he takes into account not only the market wage rate per efficient unit of labor, $w_{t+i-1}$, but the impact of his hours decision on future compensation $w_{t+i+j-1} \varepsilon_{i+j, t+i+j-1}$, for $j \geq 1$.

We consider two cases incorporating skill accumulation. First, skills may be accumulated as a by-product of working. In this learning-by-doing (LBD)

\footnotetext{
${ }^{5} \mathrm{An}$ implication of using this utility function is that the labor supply elasticity will change over the life cycle as the fraction of time spent working changes. We have also experimented with a utility function which implies a constant elasticity but found that utility function (5) delivered somewhat better results.
} 
case, we have $x=h$ in equation $(7)$ and $u_{i, t+i-1} \equiv 0$ in the lifetime utility function. As an alternative, our second case takes the opposite extreme by following Becker (1964) and Ben-Porath (1967) and assumes that skill accumulation is achieved when an individual spends time for on-the-job training (OJT). In this case, $x=u$ in equation (7).

We assume that all individuals are born with zero wealth. Furthermore, conditional on survival, the lack of a bequest motive will lead the individuals to exhaust their wealth in their last period of life. That is, we have $a_{1, t}=$ $a_{I+1, t+I}=0$ for all $t$.

\subsection{Stationary Equilibrium}

A stationary competitive equilibrium for a given set of demographic parameters $\left\{n,\left\{s_{i}\right\}_{i=1}^{I}\right\}$ consists of sequences indexed by $t$ for unintended bequests $b_{t}$, household allocations

$\left\{c_{i, t}, a_{i+1, t+1}, h_{i, t}, u_{i, t}, \varepsilon_{i+1, t+1}\right\}_{i=1}^{I}$, factor demands $K_{t}$ and $H_{t}$, and factor prices $w_{t}$ and $R_{t}$ such that

1. The household allocation solves the individuals' problem of maximizing (5) subject to (6) and (7) where $\left\{\varepsilon_{i, t}\right\}_{i=1}^{I_{R}-1}$ follows equation (7).

2. Factor demands solve the stand-in firm's profit maximization problem, which implies that

$$
\begin{aligned}
& w_{t}=(1-\alpha) e^{z_{t}}\left(\frac{K_{t}}{H_{t}}\right)^{\alpha} \\
& R_{t}=\alpha e^{z_{t}}\left(\frac{A_{t} H_{t}}{K_{t}}\right)^{1-\alpha}+1-\delta
\end{aligned}
$$

3. Aggregate quantities are obtained as weighted averages of optimal cohort decision rules where the weights are the constant population shares.

$$
\begin{aligned}
K_{t} & =\sum_{i=1}^{I}\left(a_{i, t}+b_{t}\right) \mu_{i}, \\
H_{t} & =\sum_{i=1}^{I_{R}-1} \mu_{i} \varepsilon_{i} h_{i, t}, \\
b_{t} & =\sum_{i=1}^{I-1} \frac{\mu_{i}\left(1-s_{i}\right) a_{i+1, t}}{1+n} .
\end{aligned}
$$




\section{Calibration}

To be consistent with the majority of the real business cycle literature, we calibrate the model so that one model period is equal to one quarter of a year.

\subsection{Demographics}

We first need to specify an actual age that corresponds to the first period of economic life $(i=1)$, the retirement age $\left(I_{R}\right)$, and the maximum age $(I){ }^{6}$ While the maximum age is set equal to 100 years in all experiments, the beginning and retirement ages are chosen independently in each case in order to ensure that individuals do not choose zero or negative hours before they reach age $I_{R}$. Our goal is to make the working life as long as possible subject to the fact that our solution procedure cannot handle inequality constraints $\left(h_{i, t} \geq 0\right)$ that are only sometimes binding. Hence, we choose $i=1$ to correspond to age 18 or, if $h_{1, t} \geq 0$ is binding in some states, we choose $i=1$ to be the minimum age where this constraint never binds in our simulations. Similarly we choose $I_{R}$ to be the maximum age satisfying this condition for the last working age, $i=I_{R-1}$. Therefore, while retirement age is exogenous in our model, it varies across experiments since, as $\gamma$ is reduced, individuals choose to retire earlier.

The conditional survival probabilities $\left\{s_{i}\right\}_{i=1}^{I}$ are taken from the life tables provided by the Social Security Administration (SSA) [see Bell and Miller (2002)]. They are the averages between males and females for the cohort born in 1950. The population growth rate, $n$, is assumed to be 1.2 percent per year, which is the average over 1950-2000. The steady-state efficiency profile, $\left\{\bar{\varepsilon}_{i}\right\}_{i=1}^{I_{R}-1}$, is calculated as in Hansen (1993) using updated data. This yields seven data points over the life cycle, corresponding to averages over seven age ranges, which we then interpolate to obtain human capital weights for specific ages.

\footnotetext{
${ }^{6}$ More specifically, suppose an individual starts economic life at some age $A_{0}$ (e.g. 18) and lives to some maximum age $A_{1}$ (e.g. 100). Then, given our assumption of a quarterly time interval, $I=4\left(A_{1}-A_{0}+1\right)$.
} 


\subsection{Technology and Preferences}

Many of the parameters of our model are standard in the real business cycle literature, so we calibrate them following standard practice. In particular, capital's share $(\alpha)$, the depreciation rate $(\delta)$, the discount factor $(\beta)$, and the preference parameter $A$ are chosen so that the steady state of the model matches long-run averages computed from U.S. aggregate time series data. The four statistics targeted are an average capital share of 0.36 , an average investment to output ratio of 0.25 , an average capital to output ratio of 3.0, and an average time spent working $(h+u)$ across all ages equal to 0.33 . In addition, the persistence parameter for the Solow residual $(\rho)$ is taken to be 0.95 and the standard deviation of its innovation $\left(\sigma_{\nu}\right)$ is set to 0.007 .

We consider three different values of $\gamma: 2,1$, and 0.67 . This parameter is directly related to the compensated labor supply elasticity (EIS) in our model, which is $\left(1-h_{i, t}-u_{i, t}\right) /\left(\gamma\left(h_{i, t}+u_{i, t}\right)\right)$ for an individual of age $i$. Estimates of this parameter vary considerably and range from close to 0 [MaCurdy (1981), Altonji (1986), and Browning, Deaton, and Irish (1985)] to 3.8 [Imai and Keane (2004)]. If we evaluate the labor supply elasticity at the average time spent working in our experiments (0.33), then these elasticity estimates imply values for $\gamma$ from infinity to 0.53 . Given the findings of Imai and Keane (2004), who estimate this parameter under learning by doing, lower values of $\gamma$ may be of interest. For computational reasons, we do not consider values below $0.67 .^{7}$

Table 1 below summarizes the aspects of our calibration which are invariant to the choice of $\gamma$.

\footnotetext{
${ }^{7}$ In fact, to compute results for the $\gamma=0.67$ case, we needed to not only reduce the retirement age, but to increase the age at which individuals start working.
} 


\begin{tabular}{rrr}
\hline \hline \multicolumn{1}{l}{ Table 1. Benchmark Calibration } & & \\
\hline Demographics & & \\
maximum age & $I$ & Calendar age 100 \\
population growth rate & $n$ & 0.012 (annual rate) \\
conditional survival probabilities & $\left\{s_{i}\right\}_{i=1}^{I}$ & SSA, cohort born in 1950 \\
steady state efficiency weights & $\left\{\bar{\varepsilon}_{i}\right\}_{i=1}^{I_{R}-1}$ & Hansen(1993) \\
\hline Technology & & 0.36 \\
capital share parameter & $\alpha$ & 0.0713 (annual rate) \\
depreciation rate & $\delta$ & 0.95 \\
shock persistence & $\rho$ & 0.007 \\
\hline shock standard deviation & $\sigma_{\nu}$ & \\
\hline \hline
\end{tabular}

Table 2 summarizes the calibrated values of preference parameters, first age and retirement age for given values of $\gamma$. In all cases, the calibration targets for choosing $\beta$ and $A$ are identical: $K / Y=3.0$ and $h+u=0.33$.

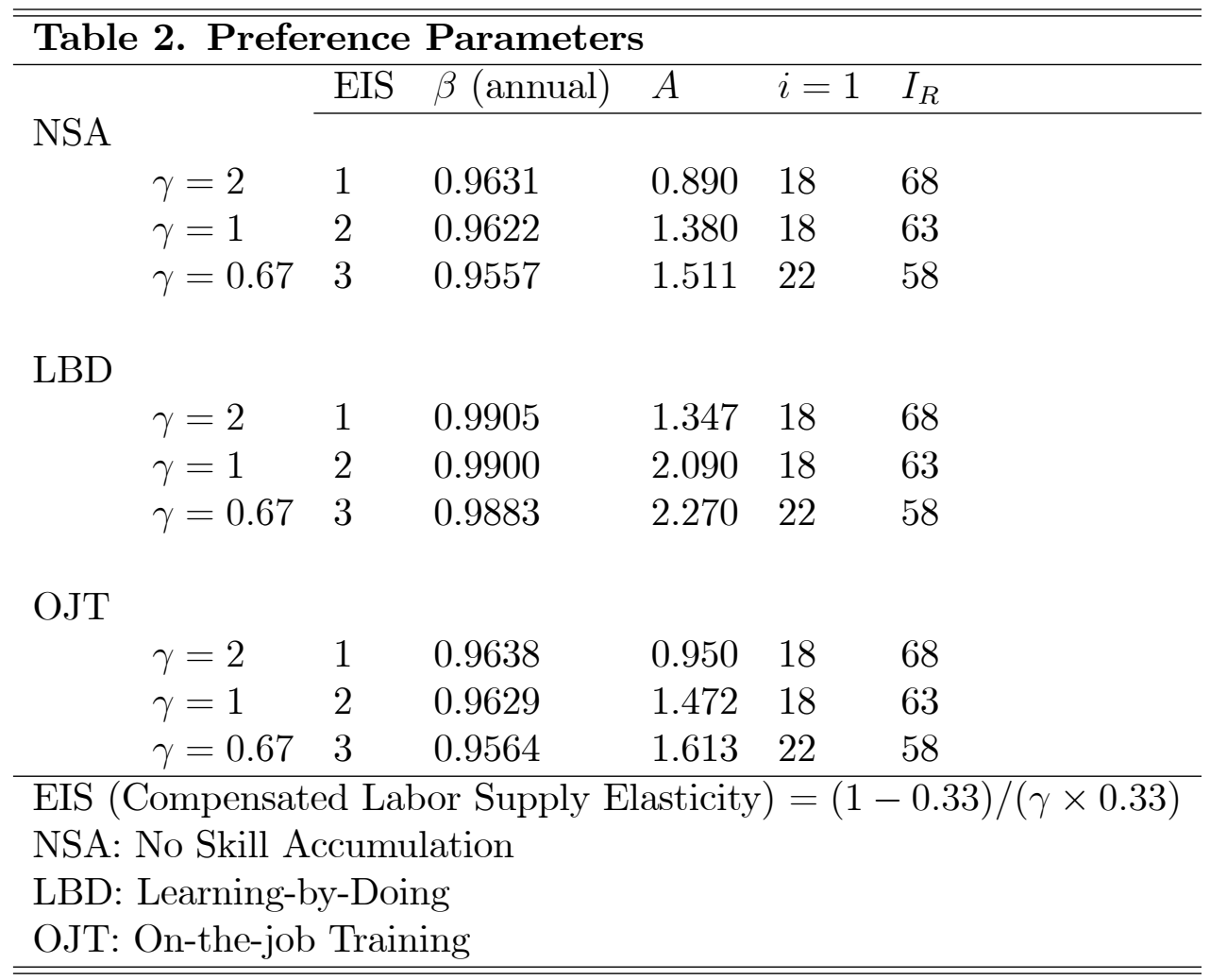




\subsection{Skill Accumulation}

We consider two skill accumulation technologies in our experiments to assess the relative importance of LBD and OJT for hours volatility over the life cycle. One has only LBD and the other only OJT. While this enables us to clearly assess the impact of each type of on-the-job skill accumulation, we are also unaware of any empirical studies that would guide us in calibrating an accumulation technology that incorporates both types simultaneously.

The skill accumulation technology (7) in the LBD case becomes,

$$
\ln \left(\frac{\varepsilon_{i+1, t+i}}{\bar{\varepsilon}_{i+1}}\right)=\phi_{1} \ln \left(\frac{\varepsilon_{i, t+i-1}}{\bar{\varepsilon}_{i}}\right)+\phi_{2} \ln \left(\frac{h_{i, t+i-1}}{\bar{h}_{i}}\right) .
$$

Our calibration of this version of the skill accumulation function follows Chang, Gomes, and Schorfheide (2002) who use PSID data set to estimate this equation. In particular, we use their posterior point estimates of $\phi_{1}=$ 0.7973 and $\phi_{2}=0.1106$.

When skill accumulation takes the form of OJT, equation (7) becomes,

$$
\ln \left(\frac{\varepsilon_{i+1, t+i}}{\bar{\varepsilon}_{i+1}}\right)=\phi_{1} \ln \left(\frac{\varepsilon_{i, t+i-1}}{\bar{\varepsilon}_{i}}\right)+\phi_{2} \ln \left(\frac{u_{i, t+i-1}}{\bar{u}_{i}}\right) .
$$

In this case, we follow Heckman, Lochner, and Taber (1998) and Kuruşcu (2006) who estimate a skill accumulation process originally proposed by Becker (1964) and Ben-Porath (1967). Their estimates imply that the lifetime profile for the ratio of time spent for OJT to market hours starts at about 40-50\% at ages 20-22 and then sharply declines to near zero by age 45 . Furthermore, the ratio of the average time spent for OJT over the lifetime to market hours is about $6 \%$. In order to reproduce these calibration targets, we set $\phi_{1}=1$ and $\phi_{2}=0.001$ in equation (7). Our choice of $\phi_{1}=1$ is in line with most of the empirical literature that assumes zero depreciation of human capital when skill accumulation is the result of OJT, as in Heckman, Lochner, and Taber (1998) and Kuruşcu (2006). A value of unity for $\phi_{1}$ provides an incentive to accumulate skills relatively early in the life cycle. 


\section{Results}

\subsection{The Importance of Age-Specific Human Capital}

As discussed in the introduction, previous work [Ríos-Rull (1996) and Gomme, Rogerson, Rupert and Wright (2004)] has established the importance of assuming a hump-shaped labor efficiency profile in order for labor market behavior in a quantitative general equilibrium life cycle model to be similar to what one finds in actual economies. While the focus of this paper is to document how the properties of the model are affected if these efficiency weights are determined by on-the-job skill accumulation, it is useful to review why age specific efficiency weights are important in the context of our particular model.

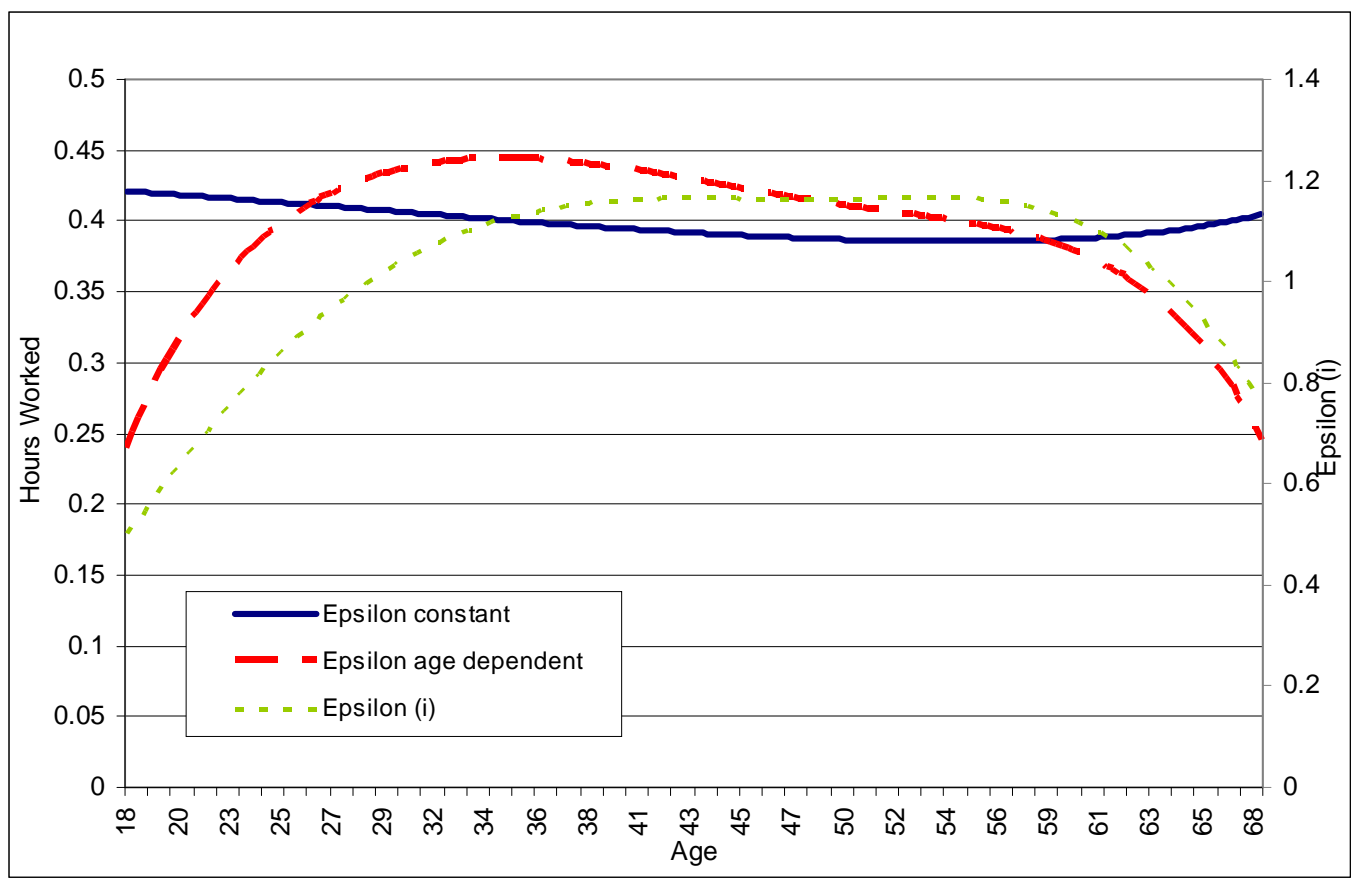

Figure 1. Steady-state Hours Profiles, gamma $=2$

Figure 1 exhibits the age-specific human capital weights we use $\left\{\bar{\varepsilon}_{i}\right\}_{i=1}^{I_{R}-1}$ (dotted curve measured along the right vertical axis) that were constructed using the methodology of Hansen (1993). The dashed line shows steady state hours worked by age computed from our model when $\gamma=2$ and equation (7) is 
ignored, setting $\varepsilon_{i, t}=\overline{\varepsilon_{i}}$ for all $t$. The figure shows that hours in our model increase early in life, decrease slightly during the prime ages, and then declines more sharply as the individual nears retirement. As will be shown in the next subsection, this is not too different from a life cycle hours profile computed from U.S. data. The solid line in Figure 1 shows steady state hours worked by age when the efficiency weights are independent of both time and age, $\varepsilon_{i, t}=\bar{\varepsilon} \equiv\left(\sum_{i=1}^{I_{R}-1} \mu_{i} \bar{\varepsilon}_{i}\right) /\left(\sum_{i=1}^{I_{R}-1} \mu_{i}\right)$ for all $t$. In this case, the hours profile is basically flat throughout the life cycle.

Figure 2 displays the volatility of hours worked by age groups using the two time invariant efficiency profiles described above. In particular, we report the means from 500 simulations of our model where the simulated data have been logged and detrended using the Hodrick-Prescott filter. With human capital constant over the life cycle, the volatility of hours rises monotonically with age. However, when the empirical hump-shaped profile is used, the standard deviation of hours over the life cycle displays a U-shape, similar to what one finds in U.S. data on hours worked by age (see next subsection).

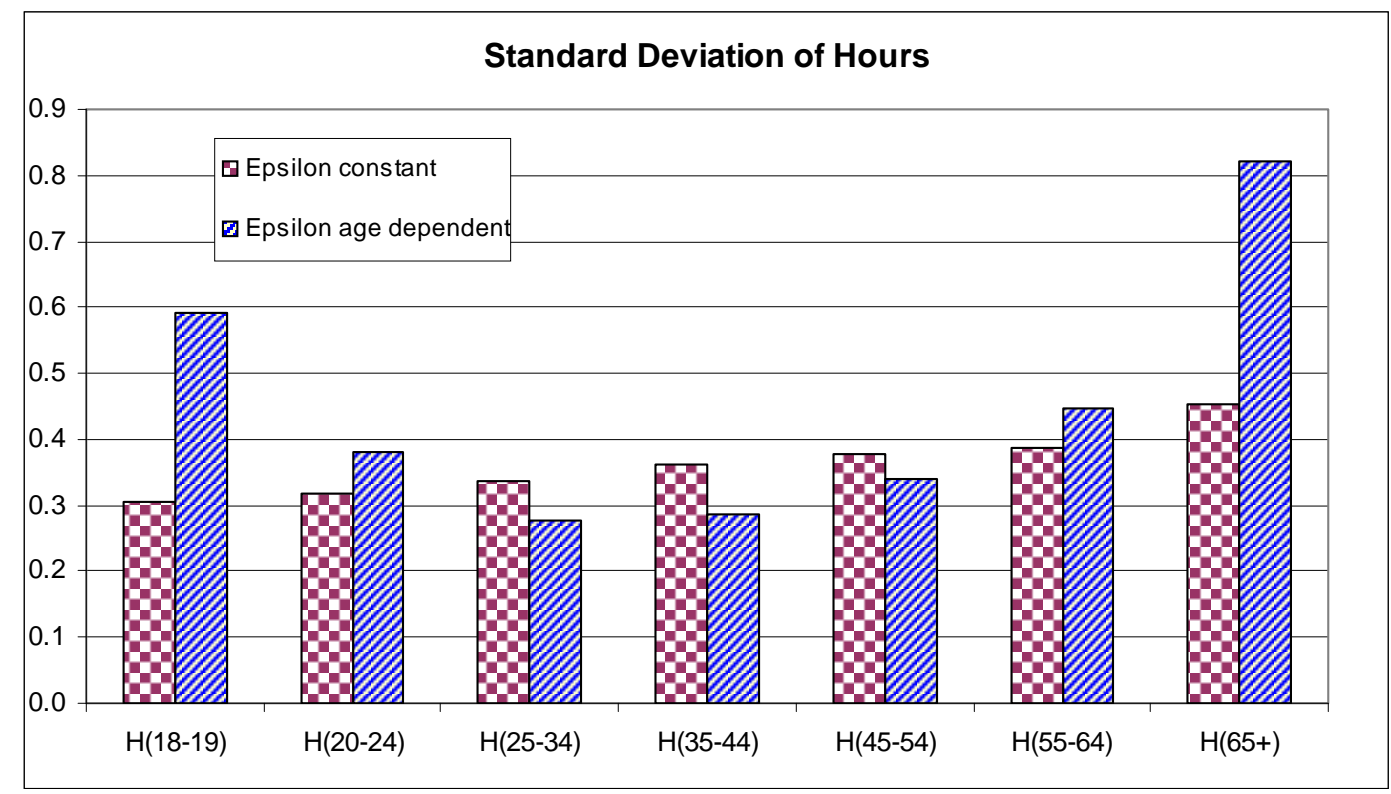

Figure 2. Hours Volatility, gamma $=2$

Given the importance of human capital that changes over the life cycle 
for both the steady state hours profile and the volatility of hours by age, we are motivated to explore the role of on-the-job skill accumulation that gives rise to differences in human capital by age.

In the remainder of this section we first examine the impact of on-the-job skill accumulation on the steady state life cycle profile of hours worked and then consider its impact on the volatility of hours worked by age. In all cases, we compare the statistics computed from the model economy with analogous statistics from U.S. data. We use quarterly averages of monthly time series on total hours at work in non-agricultural industries derived from the Current Population Survey and available from the Bureau of Labor Statistics. In particular, using this data, it is possible to construct quarterly time series for four age groups (18-24, 25-44, 45-64, 65+) from 1955Q3 to 2002Q4 and time series for seven age groups (18-19, 20-24, 25-34, 35-44, 45-54, 55-64, $65+$ ) from 1976Q3 to 2002Q4. ${ }^{8}$

\subsection{Steady-State Hours Profiles with Skill Accumula- tion}

Our empirical measure of the life cycle hours profile is the average over time of $\frac{h_{i} / \text { pop }_{i}}{h / \text { pop }}$ for each of the seven age groups, where the numerator is average hours worked per capita for age group $i$ and the denominator is average hours worked per capita for the total population. We have chosen this particular statistic because this ratio is stationary in the data and it allows us to correct for the fact that hours worked are measured in different units in the model and the data. In constructing the profiles for the model economies, we extend the retirement age as far as possible without causing steady state hours worked to be negative and report the same measure as computed from actual data.

What we find is that LBD causes individuals to work more early in life and to work less later in life. This can be seen in Figures 3a-3c. This effect becomes more pronounced as labor supply becomes more elastic (as $\gamma$ is reduced). This follows from the fact that the effective wage is higher early in life since workers are not only paid their current wage, but are rewarded in the future with higher wages due to the skill accumulated while working. It is interesting how closely the profiles match those computed from U.S. data

\footnotetext{
${ }^{8}$ Both Ríos-Rull (1996) and Gomme et. al. (2004) use annual data. Our data stops at the end of 2002 because the BLS ceased publishing hours data for all seven age groups.
} 
(see especially Figure 3b).

The life cycle hours profiles with OJT, however, are essentially identical to the profiles with no skill accumulation whatsoever. This is true for all values of $\gamma$ considered. This follows from the calibration of equation (7). Both the high value for $\phi_{1}$ and low value for $\phi_{2}$ implied by our calibration contribute to this result. In particular, since human capital does not depreciate, individuals can accumulate skills early in life and spend relatively little time on OJT later in their working life. This can be seen in the time allocated on OJT by age shown in Figure 4. In addition, the fraction of work time spent on OJT decreases rapidly with age. This is consistent with what has been found in the micro literature.

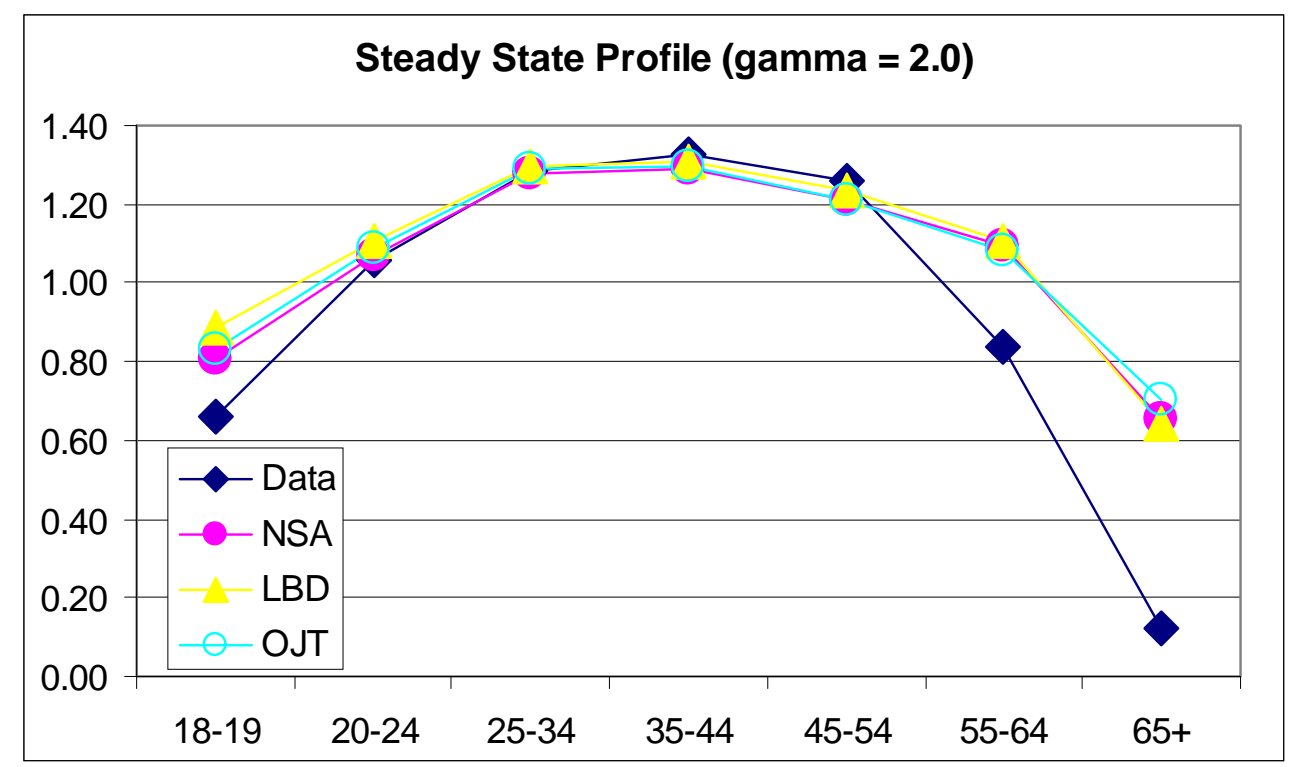

Figure 3a. Steady-state Hours Profiles, gamma $=2$ 


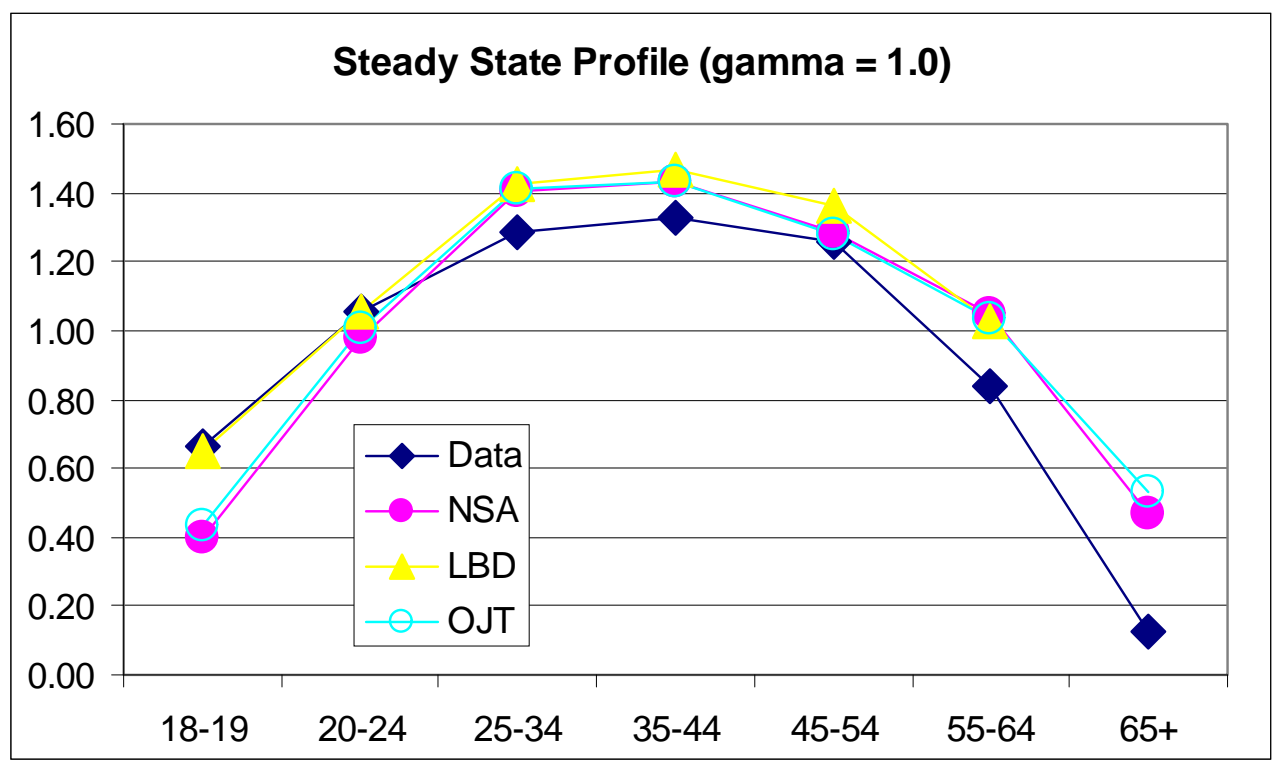

Figure 3b. Steady-state Hours Profiles, gamma $=1$

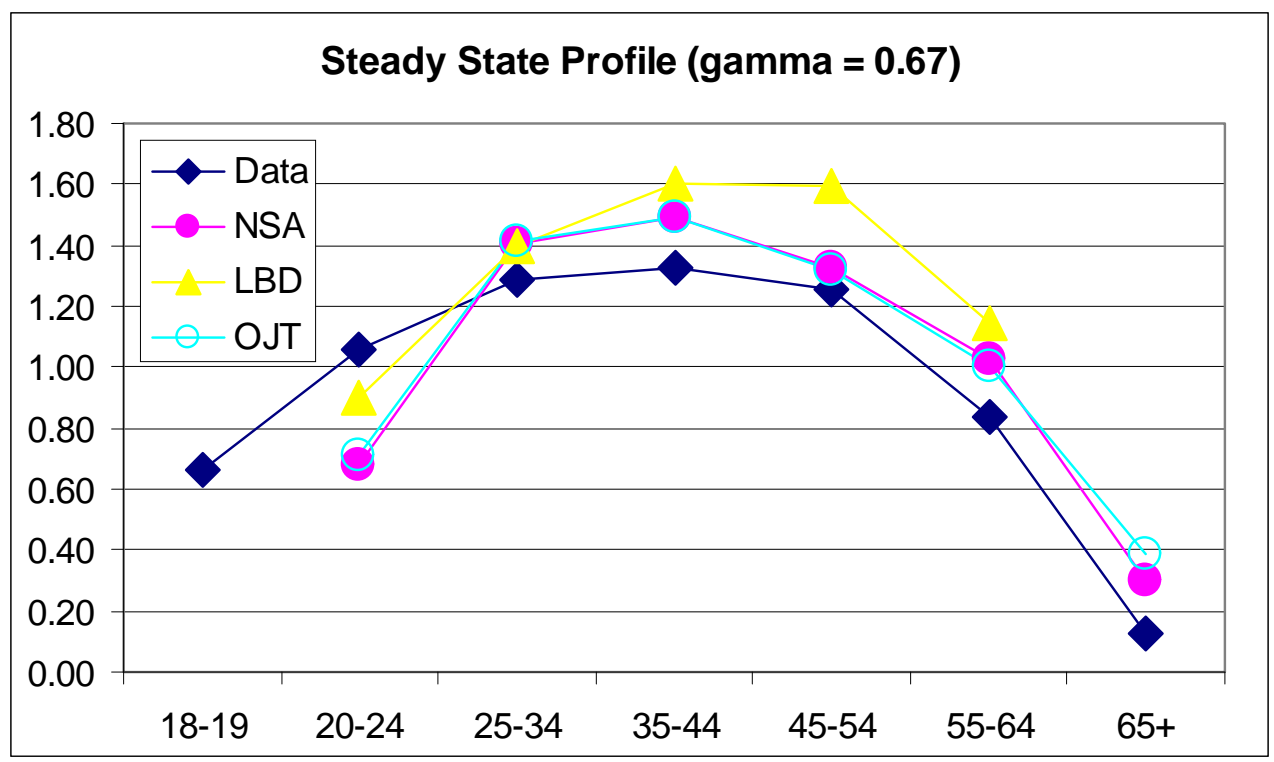

Figure 3c. Steady-state Hours Profiles, gamma $=0.67$ 


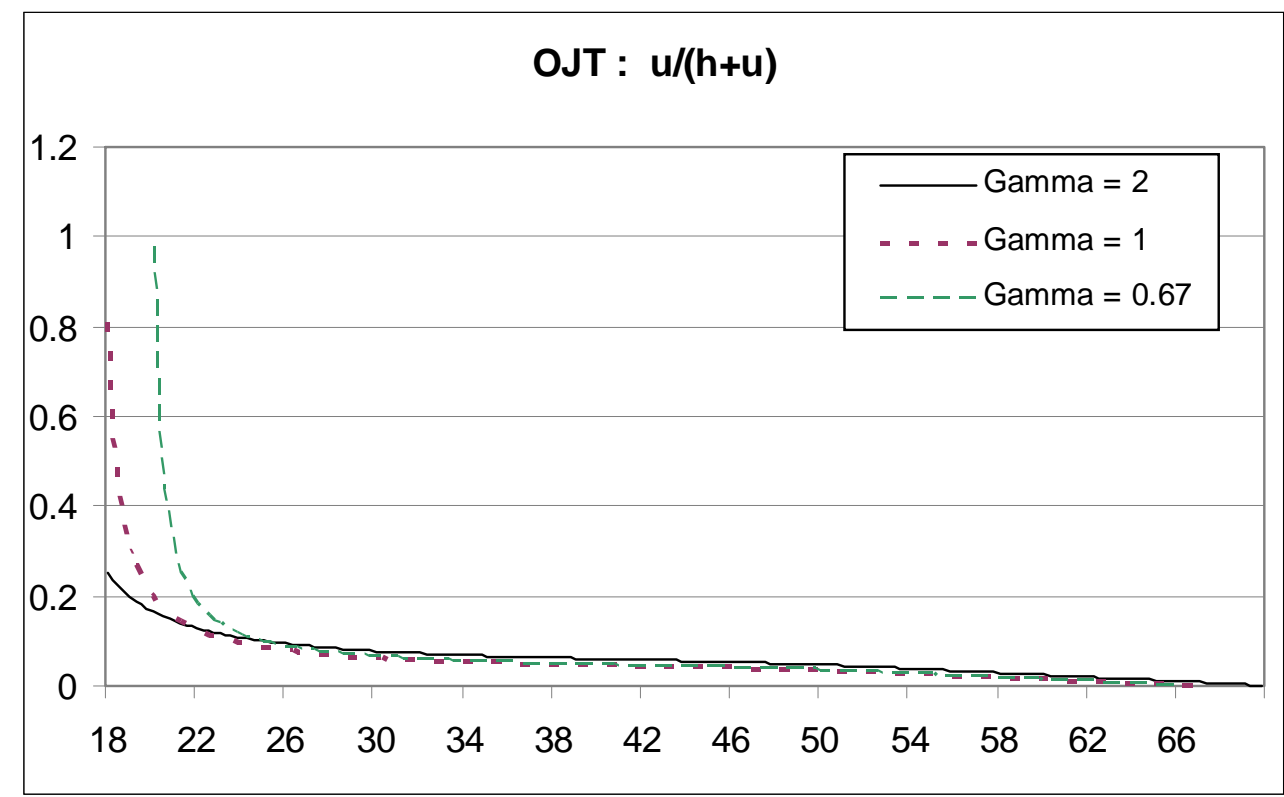

Figure 4. Ratio of Time Spent on OJT to Market Hours

\subsection{Business Cycle Properties with Skill Accumulation}

Table 3 presents business cycle statistics from the data and the calibrated models. As is standard in the literature, both the actual and the simulated quarterly series are first transformed to natural logarithms and HodrickPrescott filtered with a smoothing parameter of 1600 . The statistics displayed are the means of statistics computed from 500 simulations of the model. The volatilities are percent standard deviations from the HodrickPrescott trend. 


\begin{tabular}{|c|c|c|c|c|c|c|c|c|c|c|}
\hline \multirow[t]{2}{*}{ Ages at work: } & \multirow[b]{2}{*}{ Data } & \multicolumn{3}{|c|}{$\begin{array}{l}\gamma=2 \\
18-67\end{array}$} & \multicolumn{3}{|c|}{$\begin{array}{l}\gamma=1 \\
18-62\end{array}$} & \multicolumn{3}{|c|}{$\begin{array}{c}\gamma=0.67 \\
22-57\end{array}$} \\
\hline & & NSA & LBD & OJT & NSA & LBD & OJT & NSA & LBD & OJT \\
\hline$\sigma_{Y}$ & 1.60 & 1.12 & 1.13 & 1.13 & 1.21 & 1.35 & 1.23 & 1.24 & 1.28 & 1.26 \\
\hline$\sigma_{C}$ & 0.81 & 0.31 & 0.33 & 0.31 & 0.32 & 0.36 & 0.33 & 0.33 & 0.36 & 0.33 \\
\hline$\sigma_{I}$ & 4.56 & 3.75 & 3.76 & 3.83 & 4.11 & 4.64 & 4.19 & 4.23 & 4.28 & 4.31 \\
\hline$\sigma_{H}$ & 1.51 & 0.35 & 0.34 & 0.34 & 0.52 & 0.83 & 0.50 & 0.56 & 0.56 & 0.54 \\
\hline$\sigma_{Y / H}$ & 1.01 & 0.77 & 0.80 & 0.80 & 0.71 & 0.74 & 0.74 & 0.70 & 0.73 & 0.74 \\
\hline$\sigma_{H(18-24)}$ & 2.65 & 0.43 & 0.35 & 0.41 & 0.94 & 0.70 & 0.87 & 1.49 & 2.02 & 1.35 \\
\hline$\sigma_{H(25-44)}$ & 1.46 & 0.28 & 0.25 & 0.27 & 0.38 & 0.30 & 0.36 & 0.49 & 0.38 & 0.47 \\
\hline$\sigma_{H(45-64)}$ & 1.25 & 0.39 & 0.35 & 0.38 & 0.58 & 2.17 & 0.58 & 0.53 & 0.69 & 0.52 \\
\hline$\sigma_{H(65+)}$ & 2.55 & 0.82 & 2.36 & 0.84 & - & - & - & - & - & - \\
\hline$\rho_{Y, C}$ & 0.83 & 0.89 & 0.91 & 0.89 & 0.88 & 0.87 & 0.88 & 0.88 & 0.91 & 0.88 \\
\hline$\rho_{Y, I}$ & 0.91 & 0.99 & 0.99 & 0.99 & 0.99 & 0.99 & 0.99 & 0.99 & 0.99 & 0.99 \\
\hline$\rho_{Y, H}$ & 0.79 & 0.98 & 0.99 & 0.98 & 0.98 & 0.88 & 0.98 & 0.98 & 0.99 & 0.98 \\
\hline$\rho_{Y, Y / H}$ & 0.40 & 1.00 & 1.00 & 1.00 & 0.99 & 0.85 & 0.99 & 0.99 & 0.99 & 0.99 \\
\hline$\rho_{Y, H(18-24)}$ & 0.81 & 0.98 & 0.98 & 0.98 & 0.98 & 0.91 & 0.98 & 0.99 & 0.88 & 0.99 \\
\hline$\rho_{Y, H(25-44)}$ & 0.78 & 0.98 & 0.97 & 0.98 & 0.98 & 0.93 & 0.98 & 0.98 & 0.95 & 0.98 \\
\hline$\rho_{Y, H(45-64)}$ & 0.59 & 0.99 & 0.99 & 0.99 & 0.99 & 0.73 & 0.99 & 0.98 & 0.96 & 0.98 \\
\hline$\rho_{Y, H(65+)}$ & 0.18 & 0.99 & 0.95 & 0.99 & - & - & - & - & - & - \\
\hline
\end{tabular}

Given that the initial age and the retirement age matter for these statistics, and given that as $\gamma$ is reduced (the labor supply elasticity increased) the computationally feasible age range is narrowed (especially for the learning by doing case), we use a different initial age and retirement age for each value of $\gamma$ considered (see Table 2).

The first column of Table 3 displays the volatilities of key aggregate variables and their contemporaneous correlations with real GDP. The data over the period 1955Q3 and 2002Q4 yield a standard deviation of 1.604 for real GDP which is slightly lower than that in earlier studies, including Ríos-Rull (1996) and Gomme et. al. (2004), reflecting the moderation in fluctuations since the mid-1980s and our use of quarterly data as opposed to annual data. 
Consumption is about half as volatile as real GDP and investment is about three times as volatile as output. Total hours volatility is $94 \%$ of that of real GDP, somewhat higher than what is reported in both Ríos-Rull (1996) and Gomme et. al. (2004). Productivity is about two-thirds as volatile as output. The contemporaneous correlations of aggregate consumption, investment, hours and productivity are very similar to what has generally been reported in the real business cycle literature.

Volatility of hours over the life cycle has the U-shape that has been well documented in the previous literature. Hours' volatility is high in the 18-24 group, falls considerably in the next age group and even more so in the prime ages of 45-64 but rises sharply after age 65. Contemporaneous correlations of output and hours worked monotonically decline over the life cycle.

Table 3 also reports business cycle statistics from our calibrated economies. Our models explain about 75 percent of the fluctuations in output, although this varies somewhat depending on $\gamma$ and skill accumulation. As is typical in the real business cycle literature, model consumption is too smooth relative to data. Volatility in total hours is between 23 and $37 \%$ of that in the data and increases with a higher compensated labor supply elasticity (lower $\gamma)$. Skill accumulation has little impact on total hours volatility except for the $\gamma=1$ case when learning by doing substantially increases volatility. ${ }^{9}$ In general, skill accumulation has little effect on volatilities and correlations of aggregate variables.

Skill accumulation does, however, impact the volatility of hours worked by specific age groups. Our calibrated models deliver the general U-shape of hours volatilities over the life cycle seen in the U.S. data. However, in all cases, the volatility of hours in the 45-64 age group is higher than the volatility of the 25-44 age group, which is the opposite of what we observe in the U.S. data. This anomaly is shared in common with Ríos-Rull (1996) and Gomme et. al. (2004), and continues to hold with endogenous skill accumulation. Similarly, the model economies do not exhibit the decreasing correlation as age increases between output and hours worked by age observed in the U.S. data.

We now turn to a more detailed examination of the role played by skill accumulation on the volatility of hours worked by age (see Figure 5). In

\footnotetext{
${ }^{9}$ Comparisons across the three values of $\gamma$ is complicated by the fact that the range of working ages differs for the three cases. This definitely matters for the results obtained [see discussion in Gomme et. al. (2004)].
} 
particular, we focus on the seven age groups for which we have data from 1976Q3 to 2002Q4. In order to display the effect of skill accumulation on the volatility of hours by age, we compute the standard deviation of hours for the seven age subgroups and divide that by the standard deviation of total hours. For each value of $\gamma$, we report results from the model with no skill accumulation (NSA), the model with learning by doing (LBD) and the model with on-the-job training (OJT). For comparison, we also report the same statistic computed from the U.S. data.

We find that for all values of $\gamma$ considered, OJT makes no difference for hours volatility by age relative to the no skill accumulation (NSA) case. Once again, the main reason for this is our calibrated version of equation (7) which provides an incentive to allocate time on OJT very early in life and reduce this time to essentially zero after the first decade of working life.

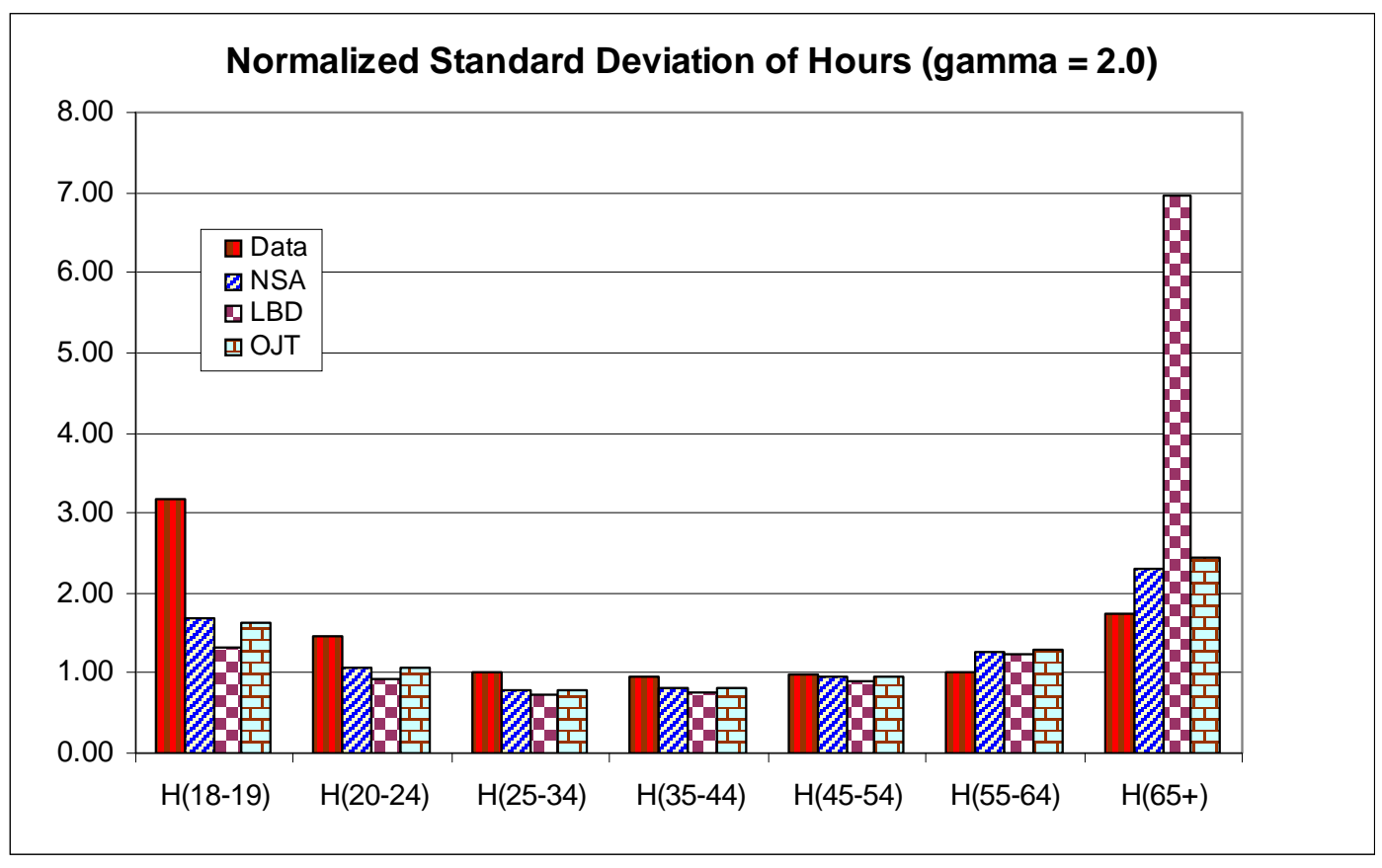

Figure 5a. Hours' Volatility, gamma $=2$

When skills are accumulated with LBD, there is some impact on hours' volatility. For $\gamma=2$, there is little impact except for workers aged 65 to 67 and somewhat for workers aged 18-19. When $\gamma$ is reduced to 1 , learning by doing significantly reduces the volatility of hours for most age groups relative 
to the case without this feature. The exception is for the oldest age group, in which case learning by doing significantly increases volatility.

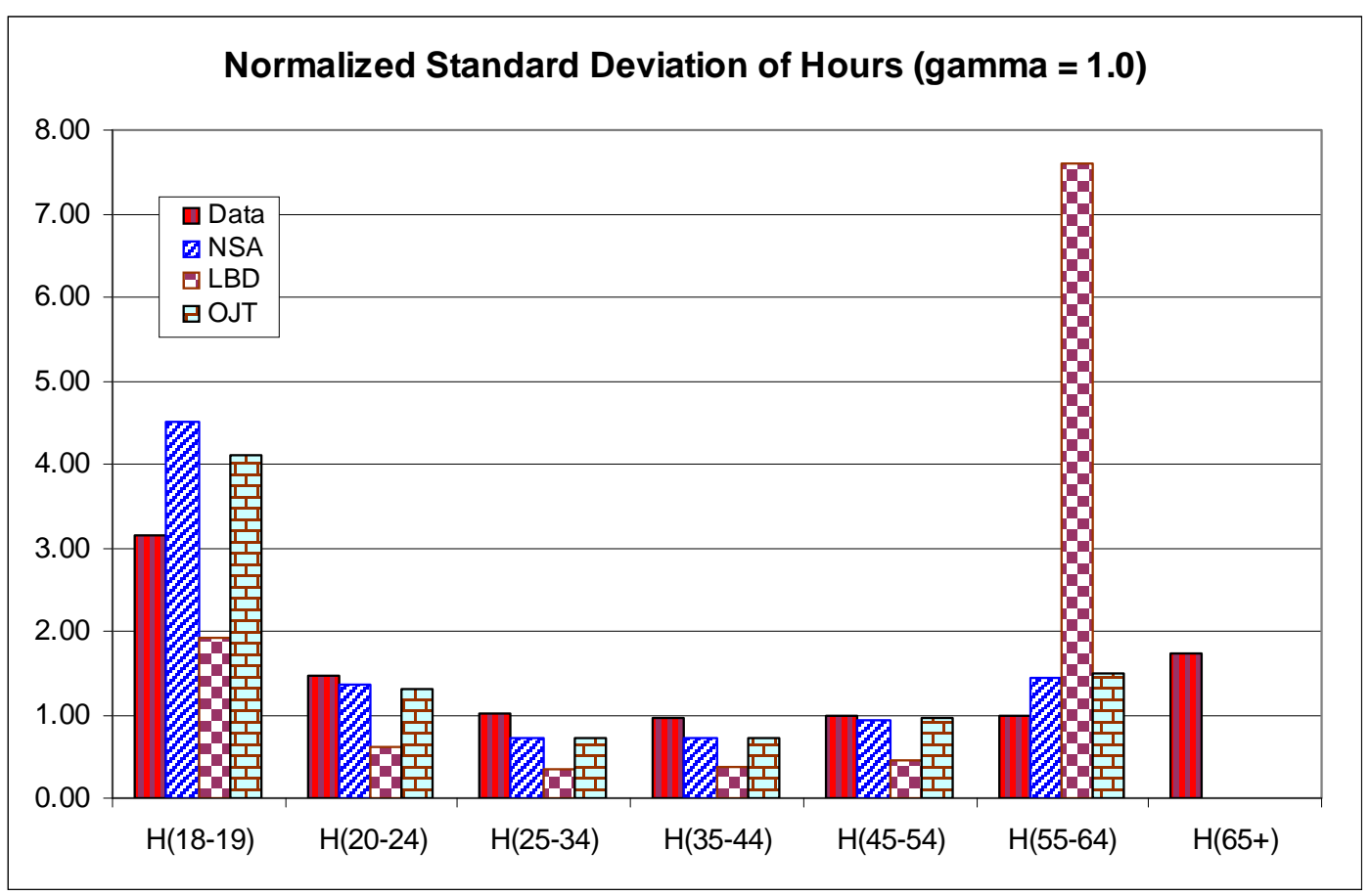

Figure 5b. Hours' Volatility, gamma $=1$

Our final case, $\gamma=0.67$, is perhaps the most empirically relevant given the findings of Imai and Keane (2004) on labor supply elasticities with learning by doing. In this case, learning by doing reduces volatility for age brackets from 25 to 54. Again, as in the $\gamma=1$ case, learning by doing significantly increases volatility for the 55-64 bracket. Unlike this case, volatility also increases volatility for the youngest age group. 


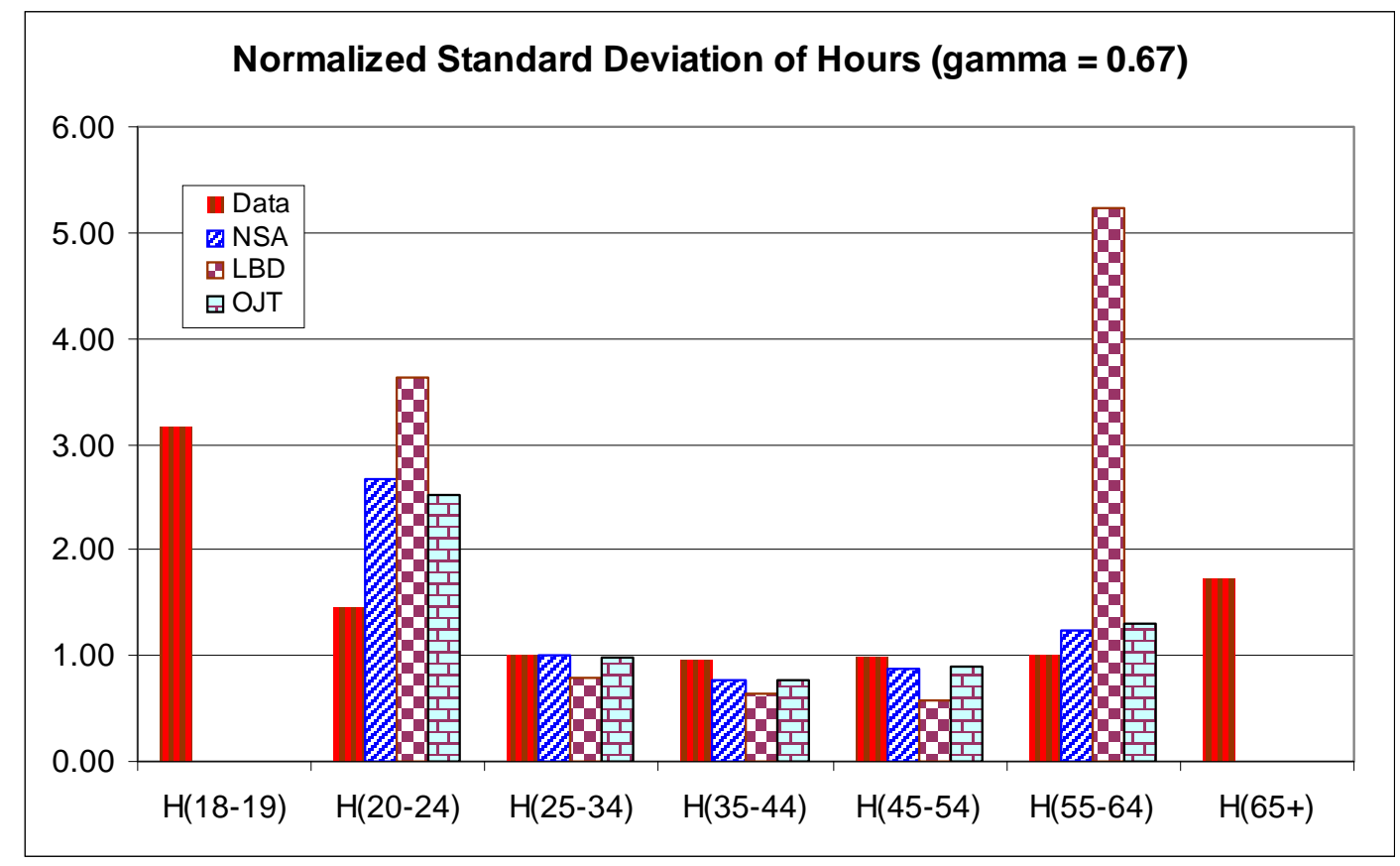

Figure 5c. Hours' Volatility, gamma $=0.67$

By adding skill accumulation to a life cycle model, we can evaluate the extent to which this feature changes the business cycle properties of the model relative to the standard (NSA) case that has been studied in the previous literature. If skills are accumulated by time devoted to OJT, then our theory predicts little impact of skill accumulation on the business cycle properties. However, if LBD is important for human capital accumulation , skill accumulation does matter. In particular, in the LBD case, the gap between the business cycle properties implied by the model and those computed from actual data is widened, primarily because individuals at the end of their working life respond more strongly to shocks.

\section{Concluding Remarks}

Hours' volatility exhibits a U-shape over the life cycle. At young and old ages, individuals seem more willing to intertemporally substitute labor than those at prime working ages. Consistent with the previous literature, this paper 
documents that this U-shape emerges from a calibrated general equilibrium life cycle model in which human capital is exogenous. When human capital changes exogenously over their working life, an individual's response to a wage shock today only affects the usual static labor/leisure trade-off and ignores the impact of current labor market decisions on future wages.

In this paper, we explore the impact of endogenizing human capital over the life cycle on the steady-state hours profile and the volatility of hours by age. We concentrate on these properties because these are features of the data present in life cycle economies, but which are absent in standard business cycle models based on the infinite horizon stochastic growth model. We consider two different technologies for skill accumulation; learning-by-doing and on-the-job training. In the former case, skill accumulation occurs as a byproduct of providing market hours, where as in the latter case the individual has to devote time for training during which no productive labor services are provided. In both cases, the individual fully incorporates the future impact of current hours' decision on future wages through a higher stock of skills in the future. We calibrate our general equilibrium life cycle economy to key long-run U.S. aggregates and relevant micro studies. In particular, we use microeconometric estimates in the labor literature to calibrate our parsimonious specification of the skill accumulation process. Future work may want to consider other forms of the human capital production function that have been explored in the micro literature, especially ones where the ability to learn might be age dependent.

Our main finding is that the introduction of OJT gives steady state and business cycle properties that are essentially identical to the case without skill accumulation. On the other hand, LBD affects both sets of properties significantly. In particular, when labor supply is more elastic, the impact of learning by doing is greater. The reason for this difference is that, in our calibrated economy, LBD affects labor market decisions at all ages, while OJT turns out to be important only during the early years of an individual's working life.

We have shown that, at least in some cases, incorporating human capital does not change the business cycle properties of our life cycle economy much compared to the case in which human capital is exogenous. Still, the life cycle model does not completely account for the pattern of hours volatility by age and the correlations of output with hours worked by age observed in the data, which leaves room for additional work on this topic. 


\section{References}

[1] Altonji, J. (1986). 'Intertemporal Substitution in Labor Supply: Evidence form Microdata', Journal of Political Economy 94: 176-215.

[2] Becker, Gary (1964). Human Capital: A Theoretical and Empirical Analysis, with Special Reference to Education,. Chicago, University of Chicago Press.

[3] Bell, F. C. and M. L. Miller (2002). 'Life Tables for the United States Social Security Area 1900-2100', Actuarial Study No. 116, Social Security Administration.

[4] Ben-Porath, Yoram (1967). 'The Production of Human Capital and the Lifecycle of Earnings,' Journal of Political Economy, 75, 352-365.

[5] Blinder, Alan and Yoram Weiss (1976). 'Human Capital and Labor Supply: A Synthesis,' Journal of Political Economy, 84, 449-472.

[6] Browning, M., A. Deaton, and Irish M. (1985). 'A Profitable Approach to Labor Supply and Commodity Demands Over the Life-Cycle', Econometrica 53: 503-543.

[7] Chang, Yongsung, Joao F. Gomes and Frank Schorfheide (2002). 'Learning-by-Doing as a Propagation Mechanism,' American Economic Review, Vol. 92(5), pages 1498-1520, December.

[8] Gomme, Paul, Richard Rogerson, Peter Rupert and Randy Wright (2004). 'The Business Cycle and the Life Cycle', NBER Macroeconomics Annual, pp. 415-461.

[9] Hansen, Gary (1993). 'The Cyclical and Secular Behaviour of the Labour Input: Comparing Efficiency Units and Hours Worked,' Journal of Applied Econometrics, Vol. 8(1), pages 71-80.

[10] Heckman, James J. (1976). 'A Life-Cycle Model of Earnings, Learning, and Consumption,' Journal of Political Economy, vol. 84(4), pages S11-44.

[11] Heckman, J., L. Lochner, and Cossa (1998). 'Explaining Rising Wage Inequality: Explorations with a Dynamic General Equilibrium Model of Labor Earnings with Heterogeneous Agents', Review of Economic Dynamics, Volume 1, pages 1-58. 
[12] Heckman, J., Lance Lochner, and C. Taber (2002). 'Explaining Rising Wage Inequality: Explorations with a Dynamic General Equilibrium Model of Labor Earnings with Heterogeneous Agents,' Review of Economic Dynamics, vol. 1(1), 1-58.

[13] Imai, S. and Keane, M. P. (2004). 'Intertemporal Labor Supply and Human Capital Accumulation', International Economic Review 45, number 2, 601-641.

[14] Jaimovich, Nir, and Henry E. Siu (2007). 'The Young, the Old, and the Restless: Demographics and Business Cycle Volatility,' Federal Reserve Bank of Minneapolis Research Department Staff Report No. 387.

[15] Kuruş̧̧u, B. (2006). 'Training and Lifetime Income,' American Economic Review, vol. 96(3), 832-846.

[16] Kydland, Finn and Edward Prescott (1982). 'Time to Build and Aggregate Fluctuations', Econometrica, 50, 1345-70.

[17] Lucas, Robert E. Jr. (1980). 'Methods and Problems in Business Cycle Theory,' Journal of Money, Credit and Banking, Ohio State University Press, vol. 12(4), pages 696-715, November.

[18] MaCurdy, T. (1981). 'An Empirical Model of Labor Supply in a LifeCycle Setting', Journal of Political Economy 89: 1059-1085.

[19] Mincer, Jacob (1974). Schooling, Experience and Earnings, Columbia University Press: New York.

[20] Ríos-Rull, Victor (1996). 'Life Cycle Economies and Aggregate Fluctuations', Review of Economic Studies 63, 465-490.

[21] Rosen, Sherwin (1976). 'A Theory of Life Earnings,' Journal of Political Economy 84 (August, part 2), S45-S67.

[22] Shaw, K. L. (1989). 'Life-Cycle Labor Supply with Human Capital Accumulation,' International Economic Review, Vol. 30(May), 431-456. 